\title{
Protein cage directed nanoparticle superlattices
}

\author{
M. A. Kostiainen \\ Department of Bioproducts and Biosystems, Kemistintie 1, Aalto University, Espoo, Finland \\ mauri.kostiainen@aalto.fi
}

Atomic crystal structure affects the electromagnetic and thermal properties of common matter. Similarly, the nanoscale structure controls the properties of higher length-scale metamaterials, for example nanoparticle superlattices and photonic crystals. We have investigated the self-assembly and characterization of binary solids that consist of crystalline arrays of 1) spherical viruses / other protein cages and 2) functional units [1]. The extremely well defined structure of protein cages (e.g. CCMV, TMV and ferritins) facilitates the construction of co-crystals with large domain sizes. The use of a second functional unit allows highly selective pre- or post-functionalization with different types of functional units, such as organic dyes [2,3], supramolecular hosts [4] and enzymes [5].

In the case of rod-like protein assemblies (e.g. tobacco mosaic virus), well-defined binary superlattice wires can be achieved [6]. The superlattice structures are explained by a cooperative assembly pathway that proceeds in a zipper-like manner after nucleation. Curiously, the formed superstructure shows right-handed helical twisting due to the right-handed structure of the virus. This leads to structure-dependent chiral plasmonic function of the material.

Our systematic approach identifies the key parameters for the assembly process (ionic strength, electrolyte valence, $\mathrm{pH}$ ) and highlights the effect of the size and aspect ratio of the virus particles, which ultimately control the crystal structure and lattice constant. Proteinbased mesoporous materials, nanoscale multicompartments and metamaterials are all applications that require such high degree of structural control.
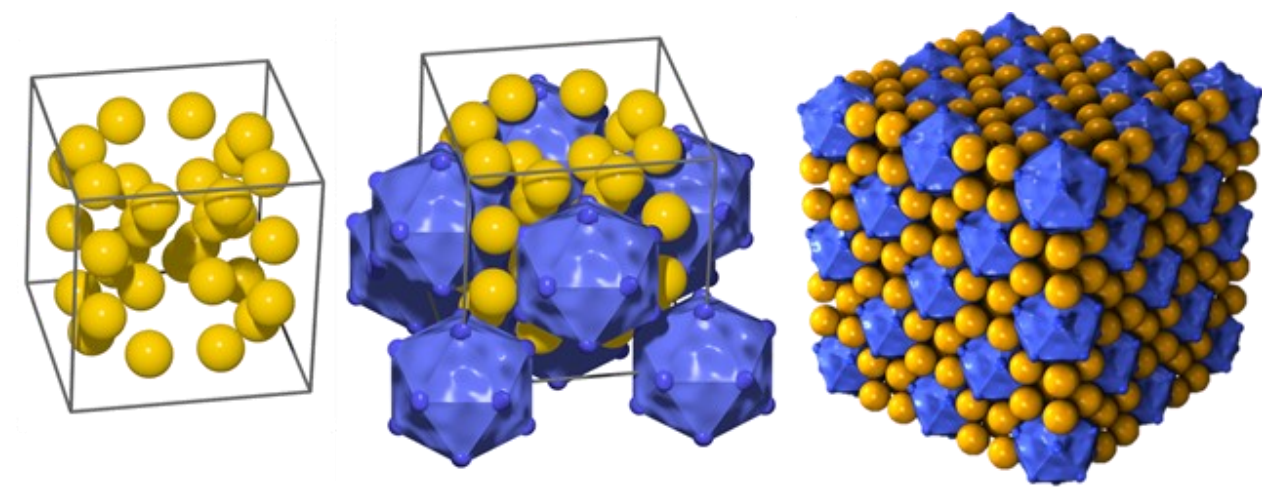

Figure 1. Electrostatic self-assembly of $\mathrm{AB}_{8}{ }^{\mathrm{fcc}}$-packed virus-gold nanoparticle superlattices.

[1] Kostiainen, M. A.; Hiekkataipale, P.; Laiho, A.; Lemieux, V.; Seitsonen, J.; Ruokolainen, J.; Ceci, P. (2013). Nat. Nanotech. 8, 52.

[2] Mikkilä, J., Anaya-Plaza, E., Liljeström, V., Caston, J. R., Torres, T.; De La Escosura, A. \& Kostiainen, M. A. (2016). ACS Nano 10, 1565.

[3] Anaya-Plaza, E., Aljarilla, A., Beaune, G., Nonappa, Timonen, J. V. I., de la Escosura, A., Torres, T. \& Kostiainen, M. A. (2019). Adv. Mat. 31, 1902582.

[4] Beyeh, N. K., Nonappa, Liljeström, V., Mikkilä, J., Korpi, A., Bochicchio, D., Pavan, G. M., Ikkala, O., Ras, R. H. A. \& Kostiainen, M. A. (2018). ACS Nano 12, 8029.

[5] Liljeström, V., Mikkilä, J. \& Kostiainen, M. A. (2014). Nature Commun. 5, 4445.

[6] Liljeström, V., Ora, A., Hassinen, J., Heilala, M., Hynninen, V., Joensuu, J., Nonappa, Rekola, H., Törmä, P., Ikkala, O., Ras, R. H. A. \& Kostiainen, M. A. (2017). Nature Commun. 8, 671.

Keywords: protein cage; virus; nanoparticle; crystal; SAXS; self-assembly; electrostatic interactions 